\title{
Health and Lifestyle Factors of Australian Medical Radiation Workers: A Pilot Study Using Nuclear Medicine Technologists
}

\author{
Samantha A. O’Brien, Daphne J. James, and Helen M. Warren-Forward \\ School of Health Sciences, University of Newcastle, Newcastle, New South Wales, Australia
}

The health effects of chronic low-dose radiation exposure are a subject of worldwide debate. These effects are difficult to assess because all low-dose exposure mechanisms must be accounted for, including background exposure, personal medical examinations, and environmental exposure such as aviation, as well as lifestyle choices contributing to disease. The current literature recommends investigation of lifestyle factors to fill in these gaps. The aim of this study was to pilot-test a survey developed to assess health and lifestyle factors for Australian medical radiation workers. Methods: A cohort of nuclear medicine technologists (NMTs) was selected to test the survey. The survey consisted of 53 questions relating to demographics, employment, lifestyle, and health. Data from the 2017-2018 Australian National Health Survey were used to compare the lifestyle choices and health of the participants with those of the Australian general population. Results: In total, 101 participants pilot-tested the survey. Overall, Australian NMTs make better lifestyle choices (more exercise, more vegetable intake, lower rates of smoking and alcohol consumption) resulting in lower rates of obesity than the Australian general population. NMTs had a higher reported health status than the Australian population, with lower levels of psychologic distress. Given the low age of NMTs participating in the study, the cancer incidence rate may be higher than that reported for the Australian general population; however, a larger sample size is required to provide more definitive results. Conclusion: This pilot study demonstrated the feasibility of conducting a widespread survey to assess health and lifestyle factors for the Australian medical radiation worker cohort. Comparison of survey results with data for the entire Australian population have highlighted the potential to increase the number of lifestyle questions.

Key Words: low-dose radiation; lifestyle factors; health; nuclear medicine technologists; medical radiation scientists

J Nucl Med Technol 2020; 48:246-253

DOI: $10.2967 /$ jnmt.119.241505

$\mathbf{O}$ ccupational dose limits for medical radiation personnel are set to ensure that stochastic effects of radiation exposure are minimized and deterministic effects are not

\footnotetext{
Received Dec. 29, 2019; revision accepted Mar. 16, 2020.

For correspondence or reprints contact: Samantha A. O'Brien, School of Health Sciences, University of Newcastle, Newcastle, New South Wales, Australia 2308.

E-mail: samantha.a.obrien@gmail.com

Published online Apr. 20, 2020.

COPYRIGHT (c) 2020 by the Society of Nuclear Medicine and Molecular Imaging.
}

manifested (1). The current recommended limit on occupational radiation exposure in medical imaging in Australia is $20 \mathrm{mSv}$ per year, averaged over $5 \mathrm{y}$, and is governed by the Australian Radiation Protection and Nuclear Safety Agency (2). This limit comes from the International Committee of Radiological Protection and is based on studies of the atomic bomb survivors of Hiroshima and Nagasaki. The atomic bomb lifespan study showed that moderate to high doses of radiation $(>150 \mathrm{mSv})$ can cause leukemia and many types of solid cancers, including those of the thyroid, breast, and lung (1). In this study, health effects were reported as unclear at doses below $100 \mathrm{mSv}$ and virtually unknown at doses below $20 \mathrm{mSv}$. This uncertainty can be attributed to the difficulty in assessing factual doses due to the evacuation of survivors after the exposure (leading to lower assessment and follow-up), variation in exposure to unrelated radiation sources such as background radiation or previous medical examinations, and inherent variation among individuals related to lifestyle risk factors and genetics (3). The atomic bomb survivors received acute exposures to high levels of radiation, unlike medical radiation workers who receive low-level chronic doses (4).

There is much worldwide debate on the safety of chronic low-dose radiation exposure. Radiation-induced cancer is widely but not universally believed to occur from exposure to low doses of ionizing radiation used in medical imaging (5). The linear nonthreshold model proposes that there are no safe levels of radiation exposure and that there is an increased risk of cancer with increasing dose (4). This risk model is currently accepted by many international authorities, including the International Committee for Radiological Protection (4) and the Committee on Health Effects to Low Levels of Ionizing Radiation (6). This model has been derived from direct extrapolation of the lifespan study data and states that a single radiation particle hitting a single DNA molecule in the human body can initiate cancer; the more radiation received, the higher the probability of a hit and therefore an increased risk (7). One of the many arguments against the linear nonthreshold model is that the human body has a natural defense mechanism consisting of DNA repair enzymes to prevent most DNA damage from turning into cancer; that is, there is a threshold at which the body can protect itself (7). Another theory is that of radiation hormesis, which advocates that small amounts of radiation may have 
beneficial rather than harmful biologic effects. There have been several cellular and molecular studies indicating that low-level exposure to radiation can cause an adaptive response, enabling protection from subsequent radiation (8). Another argument is the bystander response model. This postulates that low levels of radiation exposure may be even more damaging than the predicted linear nonthreshold model. Bystander effects describe the effect by which extracellular mediators from irradiated cells on neighboring nonirradiated cells result in radiation effects seen in those nonirradiated cells. This cell-to-cell communication is thought to enhance the effect of low radiation doses (9).

Worldwide, the literature on the health effects of low-dose radiation exposure in humans is sparse, with only 4 major scientific reports mentioning occupational exposures having been published or updated in the last $15 \mathrm{y}$. These reports place importance on all low-dose exposure mechanisms, including background exposure, medical examination exposures to patients and other environmental exposures such as aviation. However, there is a significant gap in knowledge on health effects for occupationally exposed persons who continuously receive low exposures every day in conducting their work duties. To address this gap, in 2016 the United Nations Scientific Committee on the Effects of Atomic Radiation called on all members of the United Nations to report on their occupational radiation exposures with the aim of evaluating the health risks of chronic low-dose radiation and the impact new technologies have had on occupational doses received (5).

In the field of medical imaging, the U.S. Radiologic Technologist Study is a major research investigation that has been ongoing since 1982. The study aims to investigate the health effects of low-dose occupational radiation exposure in radiologic technologists and is the largest study ever undertaken on this topic (10). Major findings of this study conclude that there was an increased cancer incidence among the 90,305 radiologic technologists surveyed between 1983 and 1998. This cohort performed either nuclear medicine or diagnostic radiography procedures or both. Female technologists showed an increased risk for solid tumors, breast cancer, and thyroid cancer. Male technologists showed an increased risk for melanoma and thyroid cancer. The researchers propose that the increased breast cancer risk is directly caused by working with low-dose ionizing radiation. They also propose that the increased prevalence of other types of cancer could be caused by an increased awareness and vigilance by the health worker, who has easier access to health-care checks. The U.S. Radiologic Technologist Study has recommended a longitudinal study and investigation into lifestyle choices (11).

In view of the significant gaps in the research on lowdose radiation, there is a need to investigate individual lifestyle choices when reporting on health data. The aim of this study was to pilot-test a survey developed to assess health and lifestyle factors for Australian medical radiation workers (diagnostic radiographers, nuclear medicine technologists [NMTs], and radiation therapists).

\section{MATERIALS AND METHODS}

The study was approved by the University of Newcastle Human Research Ethics Committee (approval H-2018-0087), and the need for written informed consent was waived because of the low risk and anonymous nature of the research.

\section{Participants}

A cohort of NMTs was selected to test the survey. NMTs registered with the Australian Health Practitioner Regulation Agency were invited to participate via an advertisement placed in the Australian Health Practitioner Regulation Agency monthly newsletter. Eligibility criteria stated that participants must have a current Australian Health Practitioner Regulation Agency registration as an NMT or provisional NMT.

Pilot testing involves formally testing a survey with a small representative sample of participants to identify any problems, such as survey format (closed, semiclosed, or open) and completeness of questions. The exact number of participants needed to pilot a survey is seen to vary in the literature, though the most cited numbers are between 10 and 30 participants (12,13). A sample size of 100 participants was considered for pilot testing the current survey.

\section{Survey Design}

The survey was based on the European Health Interview Survey and the National Statistics Office of Malta Lifestyle survey $(14,15)$. The European Health Interview Survey conducted across 17 countries contained 130 questions on demographics, health status, perceived health status, health care, and health determinants (14). The National Statistics Office of Malta lifestyle survey was more targeted and asked 39 questions relating to smoking, alcohol consumption, health, fruit and vegetable intake, and height and weight (15).

The current survey consisted of 53 questions divided into 4 sections, gathering data on demographics (3 questions), lifestyle (11 questions), employment (26 questions), and health (13 questions). Although mainly using closed-response questions, the survey included some semiclosed questions to gather a range of likely responses to be used as closed-response questions in the main survey. The survey was administered online via SurveyMonkey from July to October 2018.

\section{Data Analysis}

Quantitative data analysis was performed using descriptive statistics such as counts and frequencies. Data from the 2017-2018 Australian National Health Survey (16) were used to compare the lifestyle choices and health of NMTs with those of the Australian general population. Given the pilot nature of this research and the small number of participants, statistical differences were not assessed.

\section{RESULTS \\ Participant Size}

A total of 101 NMTs pilot-tested the survey.

\section{Demographics and Employment}

Summary demographics are presented in Table 1. Of particular note was the relatively young age of the participant group (65\% under 35 y old) who had worked in medical radiation science for less than $10 \mathrm{y}$.

\section{Lifestyle Factors}

Exercise. Very few participants (3\%) reported that they did not exercise weekly (Fig. 1), with most participants exercising between 1 and $6 \mathrm{~h}$ per week. 
TABLE 1

Summary Demographics of Participants

\begin{tabular}{|c|c|}
\hline Demographic & Percentage \\
\hline \multicolumn{2}{|l|}{ Age group (y) } \\
\hline $20-25$ & 21 \\
\hline $26-30$ & 28 \\
\hline $31-35$ & 16 \\
\hline $36-40$ & 9 \\
\hline $41-45$ & 10 \\
\hline $46-50$ & 8 \\
\hline $51-55$ & 5 \\
\hline $56-60$ & 0 \\
\hline $60+$ & 3 \\
\hline \multicolumn{2}{|l|}{ Sex } \\
\hline Male & 32 \\
\hline Female & 68 \\
\hline \multicolumn{2}{|l|}{ Employment status } \\
\hline Full-time & 70 \\
\hline Part-time & 30 \\
\hline Casual & 0 \\
\hline \multicolumn{2}{|l|}{ Type of practice } \\
\hline Public & 35 \\
\hline Private & 65 \\
\hline \multicolumn{2}{|c|}{ Years working with medical radiation } \\
\hline$<1$ & 6 \\
\hline $1-5$ & 28 \\
\hline $5-10$ & 26 \\
\hline $11-15$ & 17 \\
\hline $16-20$ & 5 \\
\hline $20+$ & 18 \\
\hline
\end{tabular}

Smoking. Eighty-six percent of participants reported to have never smoked, with $3 \%$ of participants being current smokers (Table 2). For the former smokers, the majority (64\%) quit smoking more than $5 \mathrm{y}$ previously.

\section{Dietary Intake}

Alcohol Intake. Over half $(61 \%)$ of participants reported having fewer than 4 standard alcoholic drinks per week, with male participants consuming more than female participants (Fig. 2). Consumption of $11+$ standard drinks per week was indicated by $11 \%$ of men and $5 \%$ of women.

Fruit and Vegetable Intake. Participants were asked how often, on average, they eat 2 servings of fruit per day (recommended daily intake). One piece of fruit or half a cup of canned fruit was defined as 1 serving. Around 1 in 10 participants reported doing so less than once per week. Most respondents $(43 \%)$ indicated they met the recommended daily intake 2-4 times per week. (Fig. 3). A similar percentage of women (14\%) and men (17\%) eat 2 servings of fruit every day.

Participants were asked how often, on average, they eat 5 servings of vegetables per day (recommended daily intake). A serving was defined as half a cup of cooked vegetables or 1 cup of raw vegetables. Only a small number of participants (9\%) reported doing so less than once per week. Most respondents (40\%) indicated they met the recommended daily intake 2-4 times per week (Fig. 3). The percentage of women eating 5 servings of vegetables every day was twice that of men $(15 \%$ vs. $7 \%)$.

\section{Health Factors}

Body Mass Index. The mean height of participants was $1.73 \mathrm{~m}$, with a range of $1.5-2.0 \mathrm{~m}$. The mean weight of participants was $78 \mathrm{~kg}$, with a range of $48-150 \mathrm{~kg}$. The body mass index of participants was calculated using the Australian Heart Foundation formula (weight/height ${ }^{2}$ ), where weight is measured in kilograms and height in meters (17). Participants were then classified as being underweight, healthy, overweight, or obese using the National Health and Medical Research Council body mass index classification (18). Although half the participants were considered to be in the healthy range for body mass index, $49 \%$ were classified as overweight or obese (Table 3).

Mental Health and Stress. Almost half the respondents (47\%) report feeling stressed on average at least 2-4 times per week, with $8 \%$ report feeling stressed every day (Fig. 4). Participants were asked what techniques they try to relieve the feeling of stress. Exercise was the most popular choice $(63.16 \%)$ (Table 4$)$.

Overall Health. Participants were asked how they rate their overall health; $39 \%$ reported it as very good and $6 \%$ as excellent (Fig. 5). Participants were also asked if they had been told by a doctor whether they had any medical conditions. The results are shown in Table 5. The most reported conditions were mental health $(13 \%)$ and fertility problems (7\%). Participants were asked to provide further details if they selected yes to any of the conditions. Anxiety $(77 \%)$ and depression (62\%) were the most reported mental health conditions. Polycystic ovarian syndrome (29\%), endometriosis (14\%), and structural abnormalities (14\%) were reported as the highest causes of infertility (Table 5).

Cancer Incidence. Very few (3\%) participants reported an incidence of cancer, with 1 participant reporting previous breast cancer, another reporting rectal carcinoma, with the third reporting an unspecified form of cancer.

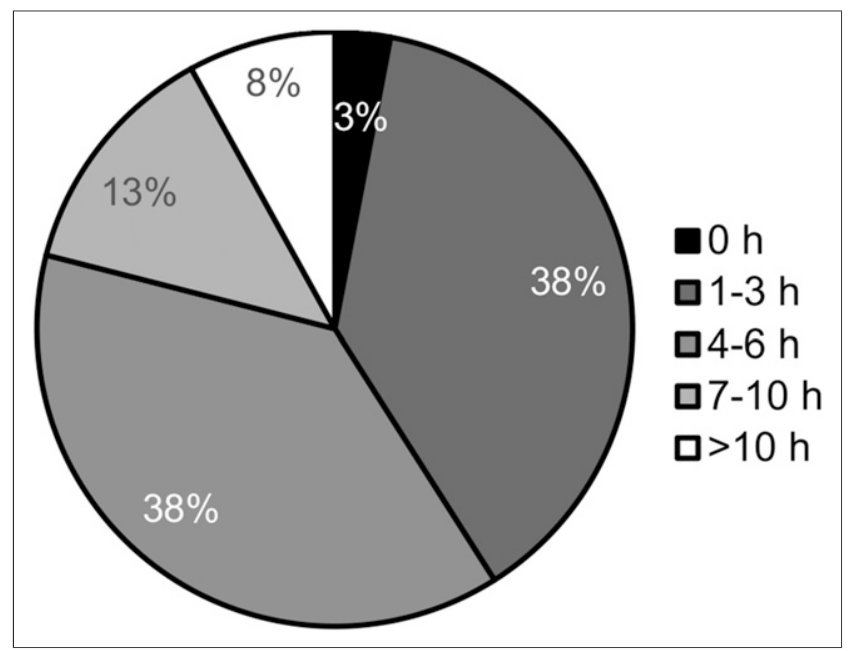

FIGURE 1. Distribution of average weekly exercise (hours) undertaken by participants. 
TABLE 2

Smoking Habits of Participants

\begin{tabular}{|c|c|c|c|c|}
\hline Smoking status & Parameter & Data & $\begin{array}{l}\text { Percentage } \\
\text { Per category }\end{array}$ & Total \\
\hline Never smoked & & & & 86 \\
\hline \multirow[t]{8}{*}{ Former smoker } & Number of cigarettes per day & $1-5$ & 55 & 11 \\
\hline & & $5-10$ & 36 & \\
\hline & & More than 10 & 9 & \\
\hline & Time since quitting & $<6 \mathrm{mo}$ & 0 & \\
\hline & & $6-12 \mathrm{mo}$ & 9 & \\
\hline & & $1-2 y(s)$ & 27 & \\
\hline & & $3-5 y$ & 0 & \\
\hline & & $>5$ y & 64 & \\
\hline \multirow[t]{7}{*}{ Current smoker } & Number of cigarettes per day & $1-5$ & 67 & 3 \\
\hline & & $5-10$ & 33 & \\
\hline & & More than 10 & 0 & \\
\hline & Number of years of smoking & $<1 \mathrm{y}$ & 0 & \\
\hline & & $1-5 y(s)$ & 33 & \\
\hline & & $5-10$ y & 67 & \\
\hline & & $>10 y$ & 0 & \\
\hline
\end{tabular}

\section{DISCUSSION}

The Australian Institute of Health and Welfare reports that the number 1 risk factor contributing to disease burden in Australia is smoking, followed by obesity, alcohol use, low levels of physical exercise, and high blood pressure (19). It has been suggested that health-care workers make better choices because they have greater health literacy, education, and patient experience to draw on (20). Helfand and Mukamal surveyed 260,558 U.S. participants, and 21,380 of those were health-care practitioners. The results showed no significant difference in lifestyle choices-mainly smoking, obesity, and alcohol consumption-between health-care practitioners and the general population (21). Dayoub and Jena compared trends in the U.S National Health Survey from 2002, 2005, 2007,2010 , and 2013. The sample contained 147,129 respondents, of whom 3,869 were health-care practitioners. The results showed that health-care practitioners did more physical activity than the general population, had lower rates of smoking, obesity, and high blood pressure, but had higher rates of excessive alcohol consumption (20).

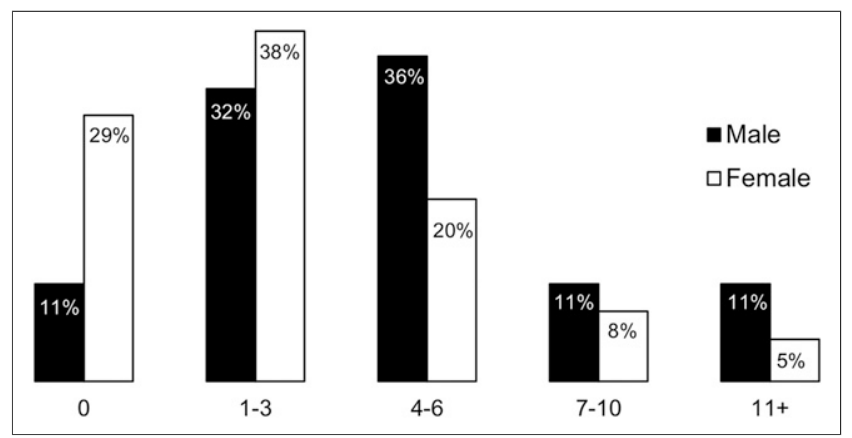

FIGURE 2. Distribution of average weekly alcohol consumption by male and female participants.

\section{Lifestyle Factors}

Exercise. Leading an inactive lifestyle can cause cardiovascular disease and increase the risk of type 2 diabetes. Sufficient physical activity is seen as 150-300 min of moderate-intensity exercise each week in adults aged 18-64 y according to the Australian Department of Health (22). In the 2017-2018 National Health Survey (16), 55\% of Australians reported undertaking $150 \mathrm{~min}$ or more of exercise in the last week. The results of this study showed NMTs to be slightly more active, with only $41 \%$ of participants being inactive or having insufficient levels of activity. This would suggest that NMTs should have lower rates of cardiovascular disease and type 2 diabetes than the general population, as they are more active. Cardiovascular disease accounted for $14 \%$ of the Australian disease burden in 2015, and type 2 diabetes accounted for $2.2 \%$ (16). In the current study, $2 \%$ of participants reported being diagnosed with cardiovascular disease and $1 \%$ with type 2 diabetes.

Smoking. Smoking is the most preventable cause of death in Australia (23). Smoking is responsible for more cancer deaths in Australia than any other factor, with each cigarette containing over 70 carcinogenic chemicals. Current smokers are estimated to die an average of $10 \mathrm{y}$ earlier than nonsmokers (24). According to the Australian 2017-2018 National Health Survey, 1 in 6 (17.5\%) Australians over 18 y of age smoke cigarettes daily (16). On the basis of these results, we would expect NMTs to have much lower cancer rates because the rate of current smokers was just $3 \%$.

\section{Dietary Intake}

Alcohol. According to the Foundation for Alcohol Research and Education, more than 144,000 Australians are hospitalized every year for alcohol-related disease (25). Alcohol causes approximately 6,000 deaths, making it the second most serious preventable health challenge behind smoking 


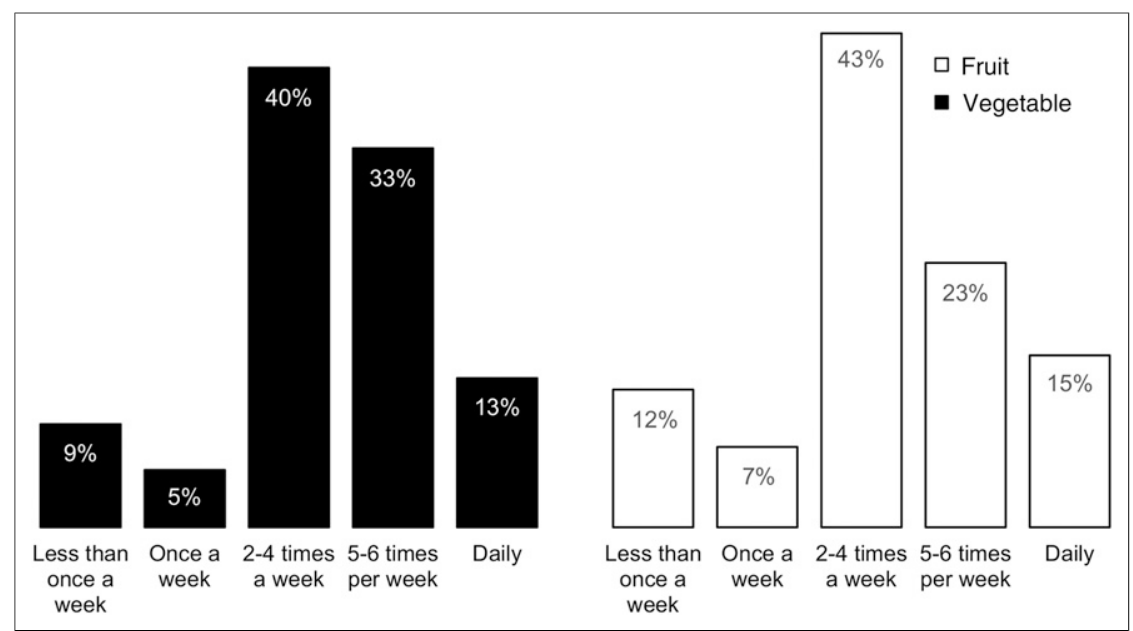

FIGURE 3. Distribution of average daily servings of fruits and vegetables consumed by participants.

(19). The 2009 National Health and Medical Research Council guidelines for reducing health risks associated with the consumption state that "drinking no more than 2 standard drinks on any day reduces the lifetime risk of harm from alcohol-related disease or injury" (26). The 2019 Foundation for Alcohol Research Education alcohol survey reported that $82 \%$ of the 1,820 Australian participants consume alcohol weekly, with more men $(85 \%)$ consuming alcohol than women $(79 \%)$. A quarter (24\%) of people responding to the survey drink 3 or more days per week, and 12\% drink 6-10 standard drinks on a typical occasion (25). The Australian 2017-2018 National Health Survey reported that 1 in 6 (16.1\%) participants over the age of $18 \mathrm{y}$ consumed more than 2 standard drinks per day (16). The results of this study showed that $76 \%$ of NMTs consume at least 1 standard alcoholic drink per week, slightly below the national average as a whole. Although twice as many male as female NMTs are more likely to exceed 11 standard drinks in a week, NMTs are, on average, less likely to exceed the National Health and Medical Research Council lifetime guidelines. Long-term alcohol use can lead to chronic conditions such as hypertension, cardiovascular disease, liver cirrhosis, dementia, mental health problems, and some cancers (16). We would expect to see a decrease in these conditions in the NMT population.

Fruit and Vegetable Intake. Diets rich in fruit and vegetables can lower blood pressure and reduce the risk of cardiovascular disease, stroke, eye disease, and digestive problems (19). In the 2017-2018 Australian National Health

TABLE 3

Distribution of Body Mass Index of Participants

\begin{tabular}{llc}
\hline Body mass index & Category & Percentage \\
\hline Less than 18.5 & Underweight & 1 \\
$18.5-24.9$ & Healthy & 50 \\
$25-29.9$ & Overweight & 27 \\
30 and over & Obese & 22 \\
\hline
\end{tabular}

Survey, just over half $(51.3 \%)$ of Australians reported that they consumed 2 or more servings of fruit per day as per the recommended daily intake. Just 1 in $13(7.5 \%)$ reported that they consumed the recommended 5 servings of vegetables daily (16). The results of the current study show that only $15 \%$ of NMTs consume the recommended 2 servings of fruit each day. However, $13 \%$ consume 5 servings of vegetables every day, which is nearly double the national average. There has been much international discussion on the dietary benefits versus effects of certain foods in the media over the last couple of years (27). Because of the increased promotion of high-protein, no-sugar diets, many people believe fruit contains excessive sugar and instead focus on a high intake of vegetables and meats $(27,28)$. The explanation for why NMTs consume lower amounts of fruit and higher amounts of vegetables could be that, as suggested by Dayoub and Jena (20), NMTs have greater health literacy and are making conscious health decisions based on current trends.

\section{Health Factors}

Body Mass Index. Obesity is the biggest risk factor for cardiac disease, type 2 diabetes, some musculoskeletal conditions, and cancers. As body mass index increases, so do the risks (23). In a 2017-2018 National Health Survey, more than 2 in 3 Australian adults were reported as being in the overweight $(35.6 \%)$ or obese $(31.3 \%)$ category (16). In the current study, just $49 \%$ of respondents fell into the overweight and obese category, well below the national average. This comparison places NMTs in better health than the general population, which should result in lower

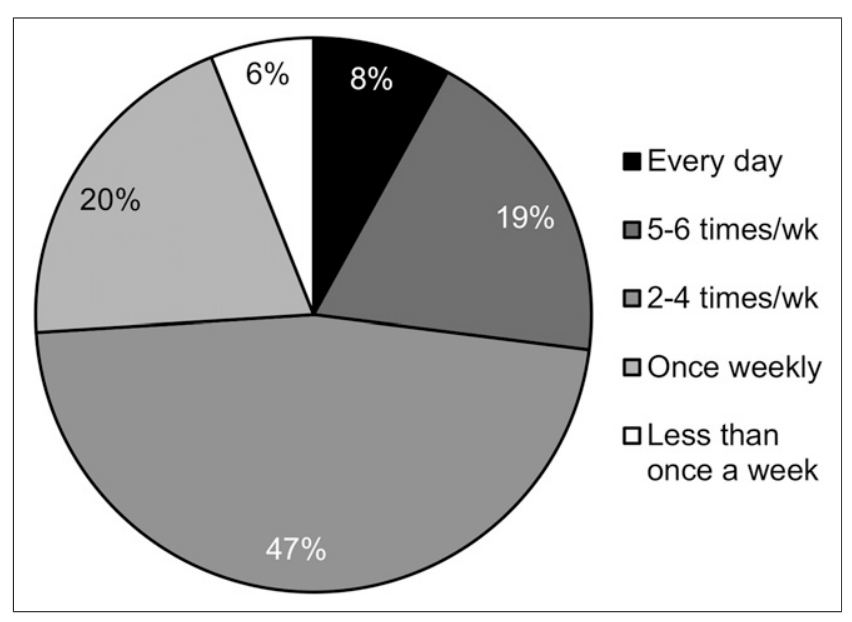

FIGURE 4. Distribution of number of times participants experience stress on average per week. 
TABLE 4

Self-Reported Techniques Used by Participants to Reduce Feelings of Stress

\begin{tabular}{|lc}
\hline \multicolumn{1}{c}{ Technique } & Percentage \\
\hline No action & 27 \\
\hline Exercise & 63 \\
\hline Meditation & 28 \\
\hline Other & 25 \\
\hline Music & 2 \\
\hline Rest & 1 \\
\hline Aromatherapy & 1 \\
\hline Counseling & 1 \\
\hline Massage & 2 \\
\hline Talking & 2 \\
\hline Breathing & 1 \\
\hline Reading & 2 \\
\hline Eating & 1 \\
\hline Float tanks & 2 \\
\hline Socializing & 1 \\
\hline Coloring & 1 \\
\hline Photography & 1 \\
\hline Sleeping & 1 \\
\hline Yoga & 1 \\
\hline Psychotherapy & 1 \\
\hline Painting & 1 \\
\hline Dealing with issue causing stress & 1 \\
\hline Mindfulness & 1 \\
\hline Completing stressful task & 1 \\
\hline Time management & 1 \\
\hline Alcohol consumption & 1 \\
\hline Hiking & 1 \\
\hline Other self-care activities & 1 \\
\hline
\end{tabular}

Some responses included multiple selections, such as meditation and exercise.

levels of cardiovascular disease, diabetes, cancer, and mental health conditions.

Mental Health and Stress. The Australian government (29) estimates that $20 \%$ of Australians have mental health

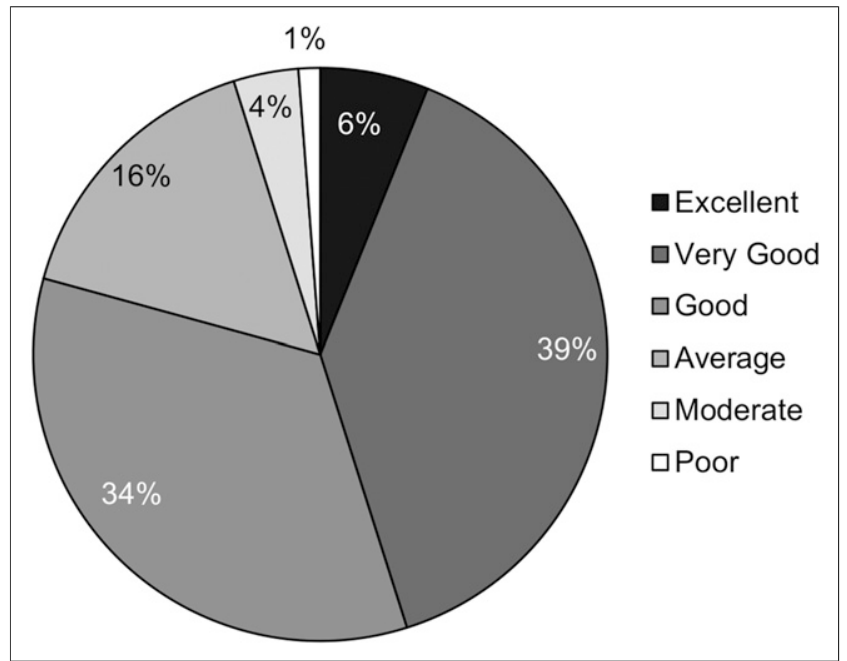

FIGURE 5. Distribution of self-reported personal health rating. disease, including depression, anxiety, dysthymia, bipolar disorder, panic disorder, agoraphobia, obsessive compulsive disorder, posttraumatic stress disorder, and substance abuse disorders. Stress from occupational causes is quickly becoming the greatest cause of occupation-induced disease (30). Chronic exposure to stressful situations has been linked to negative health outcomes such as depression, anxiety, cardiovascular disease, exhaustion, and immune disorders (31). Nearly half of respondents in this current study reported feeling work-related stress $2-4$ times per week. In the 2017-2018 National Health Survey, 13\% of Australian adults reported experiencing high or very high levels of psychologic distress and 60.8\% reported low levels of distress (16). In the current study, $13 \%$ of respondents identified as having a mental health condition; these were divided as $77 \%$ anxiety and $62 \%$ depression. Stressful working conditions are known to have an impact on employee lifestyle choices by limiting their ability to make positive changes and eliminate unhealthy behaviors (32). It is unknown what effect

TABLE 5

Medical Conditions Reported Within Participant Group

\begin{tabular}{|c|c|c|}
\hline \multirow[b]{2}{*}{ Medical condition } & \multicolumn{2}{|r|}{ Percentage } \\
\hline & Total & By subtype \\
\hline No medical conditions & 32 & \\
\hline No response & 32 & \\
\hline \multirow[t]{3}{*}{$\begin{array}{l}\text { Cancer/malignant } \\
\text { tumors }\end{array}$} & 3 & Breast cancer (33) \\
\hline & & Rectal carcinoma (33) \\
\hline & & No type given (33) \\
\hline \multirow{5}{*}{ Benign tumors } & 6 & Lipoma (16) \\
\hline & & $\begin{array}{l}\text { Focal nodular } \\
\text { hyperplasia (16) }\end{array}$ \\
\hline & & Cystadenoma (33) \\
\hline & & Gynecomastia (16) \\
\hline & & Pleomorphic adenoma (16) \\
\hline \multirow[t]{3}{*}{ Thyroid conditions } & 5 & Multinodular goitre (40) \\
\hline & & Hyperthyroidism (40) \\
\hline & & No type given (20) \\
\hline \multirow{2}{*}{$\begin{array}{l}\text { Cardiovascular } \\
\text { conditions }\end{array}$} & 2 & Pericarditis (50) \\
\hline & & No type given (50) \\
\hline Liver conditions & 1 & Obstetric cholestasis (100) \\
\hline Diabetes & 1 & Type 2 diabetes (100) \\
\hline \multirow{2}{*}{ Osteoarthritis } & 3 & No type given (33) \\
\hline & & Osteoarthritis (67) \\
\hline Rheumatoid arthritis & 1 & Rheumatoid arthritis (100) \\
\hline \multirow{2}{*}{ Autoimmune disease } & 2 & Psoriatic arthritis $(50)$ \\
\hline & & No type given (50) \\
\hline \multirow[t]{3}{*}{ Mental health conditions } & 13 & Anxiety (77) \\
\hline & & Depression (62) \\
\hline & & No type given (15) \\
\hline \multirow[t]{4}{*}{ Fertility problems } & 7 & $\begin{array}{l}\text { Polycystic ovary } \\
\text { syndrome (29) }\end{array}$ \\
\hline & & Structural (14) \\
\hline & & Endometriosis (14) \\
\hline & & No type given (43) \\
\hline $\begin{array}{l}\text { Stroke, cataracts, } \\
\text { osteoporosis, Parkinson } \\
\text { disease, or renal disease }\end{array}$ & 0 & No incidence reported \\
\hline
\end{tabular}

Some responses included multiple selections, such as thyroid and liver conditions. 
these feelings are having on individual health choices and occupational productivity.

Overall Health. Self-assessed overall health status reflects people's perception of their own health and is commonly used to provide a broad picture of a population's overall health. In the 2017-2018 National Health Survey, $56.4 \%$ of Australians reported their health to be excellent or very good (16), compared with only $45 \%$ of NMTs. Although $14.7 \%$ of adult Australians reported being in fair or poor health, NMTs fared better, with only $5 \%$ falling into these lower categories.

Cancer Incidence. According to the Australian Institute of Health and Welfare (33) the cancer incidence rate in Australia is 1 in 3 up to the age of 75 y $(33,333 / 100,000$ persons), with the mean age at cancer diagnosis being $66.3 \mathrm{y}$. This rate includes diagnoses of breast, prostate, lung, colon, lymphoma, head and neck, leukemia, malignant neoplasms, kidney, thyroid cancer, and melanoma of the skin but does not include basal cell carcinoma or squamous cell carcinoma of the skin, as these diseases do not require government notification in Australia. A small number of participants in this study reported an incident of cancer (3/101), which, if extrapolated $(3,000 / 100,000)$, indicates a much lower cancer incidence rate than in the Australian general population up to the age of $75 \mathrm{y}$. However, the greatest risk factor for most cancers is age, and the Australian cancer incidence rate for persons up to $35 \mathrm{y}$ old is 302 per 100,000 (33), which is 10 times lower than the cancer incidence rate of participants in this study. This finding may be a concern, considering that most participants $(65 \%)$ in this study identified as $35 \mathrm{y}$ of age or younger; however, participants who identified as having cancer reported to be within the age bands of 41-45 y, 46-50 y, and over $60 \mathrm{y}$. Lifestyle factors also have a large effect on cancer rates, and the pilot survey has identified NMTs to have healthier lifestyles (less smoking, less alcohol consumption, more exercise, lower levels of obesity) than the overall Australian population, meaning they should have lower rates of cancer induction. Although there may be an indication of a higher cancer incidence rate among the NMTs than among the general Australian public-linked to profession (and chronic exposure to radiation) and not lifestyle-this higher rate should be considered with caution given the very small sample size. A study with a much larger sample size is required to confirm this result.

\section{Recommendations for Larger Study}

There are approximately 18,000 medical radiation workers in Australia, with most being diagnostic radiographers. It will be important to recruit as many of these as possible to enable realistic comparisons with health (especially the cancer incidence rates) and lifestyle factors for the general Australian population. Advertising of the larger study will therefore extend outside the monthly newsletter of the Australian Health Practitioner Regulation Agency and will include social media (Twitter, Facebook), state organizations, national conferences, and the researchers' own networks. Recruitment will also involve snowballing to capture medical radiation workers who have left the profession.

Section 3 of the pilot survey contained many NMT workspecific questions, which in retrospect were irrelevant to the aims of this study. The larger survey will therefore greatly reduce the number of questions in this section. The survey will be expanded to provide more lifestyle questions around smoking, exercise, and the consumption of alcohol and more specific disease subgroups as closed questions, as a large number of participants did not provide this detailed information.

\section{CONCLUSION}

This pilot survey demonstrated the feasibility of conducting a widespread survey to assess health and lifestyle factors for the Australian medical radiation worker cohort. The results show that, overall, Australian NMTs make better lifestyle choices (more exercise, more vegetable consumption, and lower rates of smoking and alcohol consumption) resulting in lower rates of obesity than seen in the general Australian population. Most health issues are comparable to those in the general Australian population, though it would be expected that the health of NMTs who participated in this study is better than that of the general population. The results appear to suggest a higher incidence of cancer in the participant group-a finding that needs to be confirmed with a larger study (sample size).

\section{DISCLOSURE}

No potential conflict of interest relevant to this article was reported.

\section{REFERENCES}

1. Ozasa K, Shimizu Y, Suyama A, et al. Studies of the mortality of atomic bomb survivors, report 14, 1950-2003: an overview of cancer and noncancer diseases. Radiat Res. 2012;177:229-243

2. Code: radiation protection in planned exposure situations. Australian Radiation Protection and Nuclear Safety Agency website. https://www.arpansa.gov.au/ourservices/monitoring/australian-national-radiation-dose-register/information-for-workers. Published September 16, 2016. Updated August 1, 2018. Accessed June 17, 2020.

3. Shore RE. Radiation impacts on human health: certain, fuzzy, and unknown. Health Phys. 2014;106:196-205.

4. International Commission on Radiological Protection. Recommendations of the International Commission on Radiological Protection: ICRP publication 103. Ann ICRP. 2007;37:1-332.

5. Sources, effects and risks of ionizing radiation. United Nations Scientific Committee on the Effects of Atomic Radiation website. http://www.unscear.org/unscear/ en/publications/2017.html. Published 2017. Updated March 30, 2018. Accessed June 17, 2020.

6. Health Risks from Exposure to Low Levels of Ionizing Radiation: BEIR VII Phase 2. Washington, D.C.: National Academies Press; 2006.

7. Tanooka H. Threshold dose response in radiation carcinogenesis: an approach from chronic beta-irradiation experiments and a review of non-tumour doses. Int J Radiat Biol. 2001;77:541-551.

8. Toxicological profile for radon: appendix D-overview of basic radiation physics, chemistry and biology. NCBI website. https://www.ncbi.nlm.nih.gov/books/ NBK158792/. Accessed June 17, 2020.

9. Marcu L. Cellular bystander effects and radiation hormesis. Ann Univ Oradea. 2009;16:66-70.

10. USRT publications. National Cancer Institute website. https://radtechstudy.nci.nih. gov/publications.php. Updated April 22, 2020. Accessed June 17, 2020.

11. Sigurdson AJ, Doody MM, Rao RS, et al. Cancer incidence in the U.S. Radiologic Technologists Health Study, 1983-1998. Cancer. 2003;97:3080-3089. 
12. Hill R. What sample size is "enough" in internet survey research? IPCT-J. 1998;6: 3-4.

13. Isaac S, Michael WB. Handbook in Research and Evaluation. San Diego, CA: Edits Pub; 1995.

14. EHIS wave 1 guidelines. European Commission website. https://ec.europa.eu/ eurostat/documents/203647/203710/EHIS_wave_1_guidelines.pdf/ffbeb62c-8f644151-938c-9ef171d148e0. Updated January 15, 2010. Accessed June 17, 2020.

15. Lifestyle survey: 2006. National Statistics Office website. https://nso.gov.mt/en/ nso/Sources_and_Methods/Unit_01/Methodology_and_Research/Documents/ Questionnaires/Lifestyle_Survey_2006.pdf. Accessed June 17, 2020.

16. National Health Survey: First Results, 2017-18. Canberra, Australia: Australian Bureau of Statistics; 2019.

17. What's your BMI? Heart Foundation website. https://www.heartfoundation.org.au/ your-heart/know-your-risks/healthy-weight/bmi-calculator. Accessed June 17, 2020.

18. Clinical Practice Guidelines for the Management of Overweight and Obesity in Adults, Adolescents and Children in Australia. Canberra, Australia: National Health and Medical Research Council; 2013.

19. Australian Burden of Disease Study: Impact and Causes of Illness and Death in Australia 2011. Canberra, Australia: Australian Institute of Health and Welfare; 2016.

20. Dayoub E, Jena AB. Chronic disease prevalence and healthy lifestyle behaviours among US health care professionals. Mayo Clin Proc. 2015;90:1659-1662.

21. Helfand BK, Mukamal KJ. Healthcare and lifestyle practices of healthcare workers: do healthcare workers practice what they preach? JAMA Intern Med. 2013; 173:242-244.

22. Australia's physical activity and sedentary behaviour guidelines and the Australian 24-hour movement guidelines. Australian Government Department of Health website. http://www.health.gov.au/internet/main/publishing.nsf/Content/ health-pubhlth-strateg-phys-act-guidelines\#apaadult. Updated April 12, 2019. Accessed June 17, 2020.
23. Risk factors to health. Australian Institute of Health and Welfare website. https:// www.aihw.gov.au/reports/biomedical-risk-factors/risk-factors-to-health/contents/ risk-factors-and-disease-burden. Updated August 7, 2017. Accessed June 17, 2020.

24. Smoking. Cancer Council website. https://www.cancer.org.au/preventing-cancer/ smoking-and-tobacco/smoking.html. Updated May 28, 2019. Accessed June 17, 2020 .

25. 2019 annual alcohol poll: attitudes and behaviours. Foundation for Alcohol Research and Education website. http://fare.org.au/wp-content/uploads/FAREAnnual-Alcohol-Poll-2019-FINAL.pdf. Published 2019. Accessed June 17, 2020.

26. National Health and Medical Research Council. Australian Guidelines to Reduce Health Risks from Drinking Alcohol. Canberra, Australia: Commonwealth of Australia; 2009.

27. Kane E. Carbs: good or bad for you? Better Nutrition. 2019;81:22-23.

28. Easter M. Keto nation. Men's Health. 2019;34:112-115.

29. Prevalence of mental disorders in the Australian Population. Australian Government Department of Health website. https://www1.health.gov.au/internet/ publications/publishing.nsf/Content/mental-pubs-m-mhaust2-toc $\sim$ mental-pubs-mmhaust2-hig mental-pubs-m-mhaust2-hig-pre. Updated May 2009. Accessed June 17, 2020.

30. Leigh J, Schnall P. Costs of occupational circulatory disease: state of the art reviews. Occup Med. 2000;15:22-45.

31. Michie S, Williams S. Reducing work related psychological ill health and sickness absence: a systematic literature review. Occup Environ Med. 2003;60: $3-9$.

32. Landsbergis PA, Schnall P, Dietz D, et al. Job strain and health behaviors: results of a prospective study. Am J Health Promot. 1998;12:237-245.

33. Cancer data in Australia. Australian Institute of Health and Welfare website. https://www.aihw.gov.au/reports/cancer/cancer-data-in-australia/contents/summary. Updated June 2, 2020. Accessed June 17, 2020. 